\title{
El Parmaklarının Cerrahisinde Uyanık Hasta Anestezisinin Aksiller Anestezi ile Karşılaştırılması
}

\author{
İbrahim Avşin Öztürk, ${ }^{1}$ Kahraman Öztürk, ${ }^{2}$ Osman Orman, ${ }^{2}$ Mehmet Baydar, ${ }^{3}$ Serkan Aykut, ${ }^{2}$ Ahmet Köse ${ }^{1}$ \\ 'Erzurum Bölge Eğitim ve Araştırma Hastanesi, Sağlık Bilimleri Üniversitesi, Ortopedi Bölümü, Erzurum \\ ${ }^{2}$ Metin Sabancı Kılıç ve Eklem Hastalıkları Eğitim ve Araştırma Hastanesi, Sağlık Bilimleri Üniversitesi, El Cerrahisi Anabilim Dalı, İstanbul \\ ${ }^{3}$ Adana Numune Eğitim ve Araştırma Hastanesi, El Cerrahisi Anabilim Dalı, Adana
}

\begin{abstract}
Özet
Amaç: Uyanık hasta anestezisi (wide awake anesthesia) hastalara sedasyon yapılmadan ve turnike kullanılmadan yapılan; içeriği lidokain, epinefrin ve bikarbonattan oluşan ve el cerrahisinde geniş kullanım potansiyeli olan bir lokal anestezi türüdür. Epinefrinin cerrahlar arasında parmaklarda dolaşım bozukluğuna yol açabileceği yönündeki inanışın son yıllarda yapılan çalışmalarla ortadan kalkması ile kullanımı artmıştır.

Yöntem: Ocak 2015 ile Şubat 2016 ayları arasında Baltalimanı Kemik Hastalıkları Eğitim ve Araştırma Hastanesi El Cerrahisi kliniğinde uyanık hasta anestezisi ile ve aksiller anestezi ile gerçekleştirilen olgularda parmakları ilgilendiren hastalığı olan 52'şer hastanın hastanede ameliyata başlama zamanı, kalış süreleri, maliyeti ve hasta memnuniyeti karşılaştırıldı. Hasta memnuniyeti için ameliyat sonrası hastalara "Bu yaşadığın tecrübeyi tekrar yaşaman gerekse aynı anestezi yöntemini kabul eder miydin?" sorusu yöneltildi. Her iki grupta 26'şar adet olguda kemik girişimleri (falanks kırığı, kemik biyopsisi, implant çıkarımı ve interfalangial eklem artrodez); 26'şar adet olguda yumuşak doku girişimleri (dijital sinir onarım, parmak ucu flep, flep ayrımı, eklem kontraktur gevşetme, bağ tamiri, debridman) olacak şekilde oluşturuldu.

Bulgular: Her iki gruptaki hastada operasyonu sürdürecek oranda yeterli anestezinin sağlandığı görüldü. Operasyon sonrası hastalara “Bu yaşadığın tecrübeyi tekrar yaşaman gerekse aynı anestezi yöntemini kabul eder miydin?" sorusu yöneltilğinde aksiller anestezi grubundaki hastaların 26 olumlu, 16 olumsuz, 10 kararsız olarak; uyanık hasta anestezisi grubunda ise 33 olumlu, 7 olumsuz, 12 karasız olarak gözlendi. Hasta maliyeti (Sosyal Güvenlik Kurumu -SGK-verilerince); aksiller anestezi grubunda ortalama $316.1 \mathrm{TL}$, uyanık hasta anestezisi grubunda ortalama 25.3 TL olarak hesaplandı. Hastanede kalış süresinin aksiller anestezi grubunda ortalama 32.9 saat, uyanık hasta anestezisi grubunda ortalama 13.6 saat olduğu belirlendi. Anestezi sonrası ameliyata başlama süresinin aksiller anestezi grubunda ortalama 34 dakika, uyanık hasta anestezisi grubunda ortalama 5.3 dakika olduğu görüldü.

Sonuç: Çalışmamızda uyanık hasta anestezisi kullanarak tedavi ettiğimiz hastaların hastanede kalış sürelerinde ortalama 19.3 saat azalma; anestezi maliyetinde ise ortalama 290.8 TL azalma tespit edildi. Hastaların anestezi sonrası ameliyata başlama zamanında da ortalama 29.7 dakika düşüş sağlandı. Hasta memnuniyeti oranı uyanık hasta grubunda daha fazlaydı. Hastalarda operasyona mani olacak kanama, hasta uyumsuzluğu ve diğer ek komplikasyonlara da rastlanmadı.
\end{abstract}

Anahtar sözcükler: Anestezi; kanama; uyanık hasta.

Atıf için yazım şekli: "Öztürk I.A, Öztürk K., Orman O., Baydar M., Aykut S., Köse A. Comparison of the Cost and Efficacy of Axillary Anesthesia and Wide-Awake Anesthesia in Finger Surgeries. Med Bull Sisli Etfal Hosp 2018;52(2):119-123".

Yazışma Adresi: Ahmet Köse, MD. Erzurum Bölge Eğitim ve Araştırma Hastanesi, Sağlık Bilimleri Üniversitesi, Ortopedi Bölümü, Erzurum, Turkey Telefon: +905066330520 E-posta: kose.ahmet.46@hotmail.com

Başvuru Tarihi: 26.09.2017 Kabul Tarihi: 01.12.2017 Online Yayımlanma Tarihi: 12.06.2018

๑Telif hakkı 2018 Şişli Etfal Hastanesi Tıp Bülteni - Çevrimiçi erişim www.sislietfaltip.org

This is an open access article under the CC BY-NC-ND license (http://creativecommons.org/licenses/by-nc/4.0/). 
U yanık hasta anestezisi (wide awake anestezi) hastalara sedasyon yapılmadan ve turnike kullanılmadan yapılan; içeriği lidokain, epinefrin ve bikarbonattan oluşan ve el cerrahisinde geniş kullanım potansiyeli olan bir lokal anestezi türüdür. ${ }^{[1]}$ Epinefrinin cerrahlar arasında parmaklarda dolaşım bozukluğuna yol açabileceği yönündeki inanışının son yıllarda yapılan çalışmalarla ortadan kalkması ile kullanımı artmıştır. ${ }^{[2-6]}$ Uyanık hasta anestezisi el cerrahisinde tendon onarımları, açık-kapalı kırık fiksasyonu, tenoliz, tendon transferleri, karpal tünel gevşetme, tetik parmak, el bilek artroskopisi gibi amaliyatların yanı sıra el bileği, ön kol ve dirsek ameliyatlarında da kullanılır hale gelmiştir. ${ }^{[7-11]}$ Bu operasyonların uyanık hasta anestezisi ile yapılır olmasıyla hastanın ameliyat süresi ve hastanede kalış süresi kısalmakta, maliyet düşmekte ve en önemlisi ameliyat sırasında parmağın işlevsel durumu hakkında da anında bilgi alınmaktadı. ${ }^{[9]}$

Çalışmamızda Ocak 2015 ile Şubat 2016 ayları arasında uyanık hasta anestezisi ve aksiller anestezi ile gerçekleştirilen parmakları ilgilendiren hastalığı olan 52'şer hastanın hastanede kalış süreleri, maliyeti ve hasta memnuniyeti karşılaştırılmıştır.

\section{Yöntem}

İçeriği 1:100.000'lik adrenalinli \% 1'lik lidokain solüsyonun her 10 cc başına 1 cc \%8.4'lük bikarbonat eklenerek karışım hazırlanmıştır. Solüsyon ilgili parmağın volar veya dorsal bölgesine, metakarp ortasına, metakarpofalangeal (MF) ek- lem hizasına, proksimal interfalangeal eklem (PIF) hizasına 2 'şer cc, distal interfalangeal eklem (DIF) hizasına 1cc orta hattan yapılarak bölgenin solüsyon ile şişirilerek beyazlaşması sağlandı ve ağrı hissi kaybolana kadar beklendikten sonra ameliyata başlandı (Şekil 1). Gereğinde yarım miktar doz tekrar uygulandı. Cerrahi süre 2 saatten uzun sürecek ise solusyona 6 cc bupivakain eklendi.

Ocak 2015 ile Aralık 2015 ayları arasında Baltalimanı Kemik Hastalıkları Eğitim ve Araştırma Hastanesi El Cerrahisi Kliniği'nde uyanık hasta anestezisi ve aksiller anestezi ile gerçekleştirilen elli ikişer hastanın operasyonları, hastanede kalış süreleri, kanama miktarları, ağrı derecesi (Görsel analog skor), maliyeti çıkarıldı.

Her iki grupta 26'şar adet olguda kemik girişimleri; falanks kırığı, kemik biyopsisi, implant çıkarımı ve interfalangial (IF) eklem artrodezi; 26'şar adet olguda yumuşak doku girişimleri; dijital sinir onarım, parmak ucu flep, flep ayrımı, eklem kontraktür gevşetme, tendon ve bağ tamiri ile debridman bulunmaktaydı. Uyanık hasta anestezisi ile yumuşak doku girişimsel işlem uygulanan hastaların yaş ortalaması 39.7 (18-64), 11'i kadın, 15'i erkekti. Anestezi maliyeti ortalaması 26.8 TL (18.5-48.5), ortalama hastanede yatış süresi 14.3 saat (6-33), ameliyata başlama süresi ortalama 5.3 dakika (3-8) olarak değerlendirildi. Uyanık hasta anestezisi ile girişimsel kemik işlem uygulanan hastaların yaş ortalaması 38 (18-70), 11'i kadın, 15'i erkekti. Anestezi maliyeti ortalaması 24.9 TL (18.5-48.5), ortalama hastanede yatış süresi 14.3

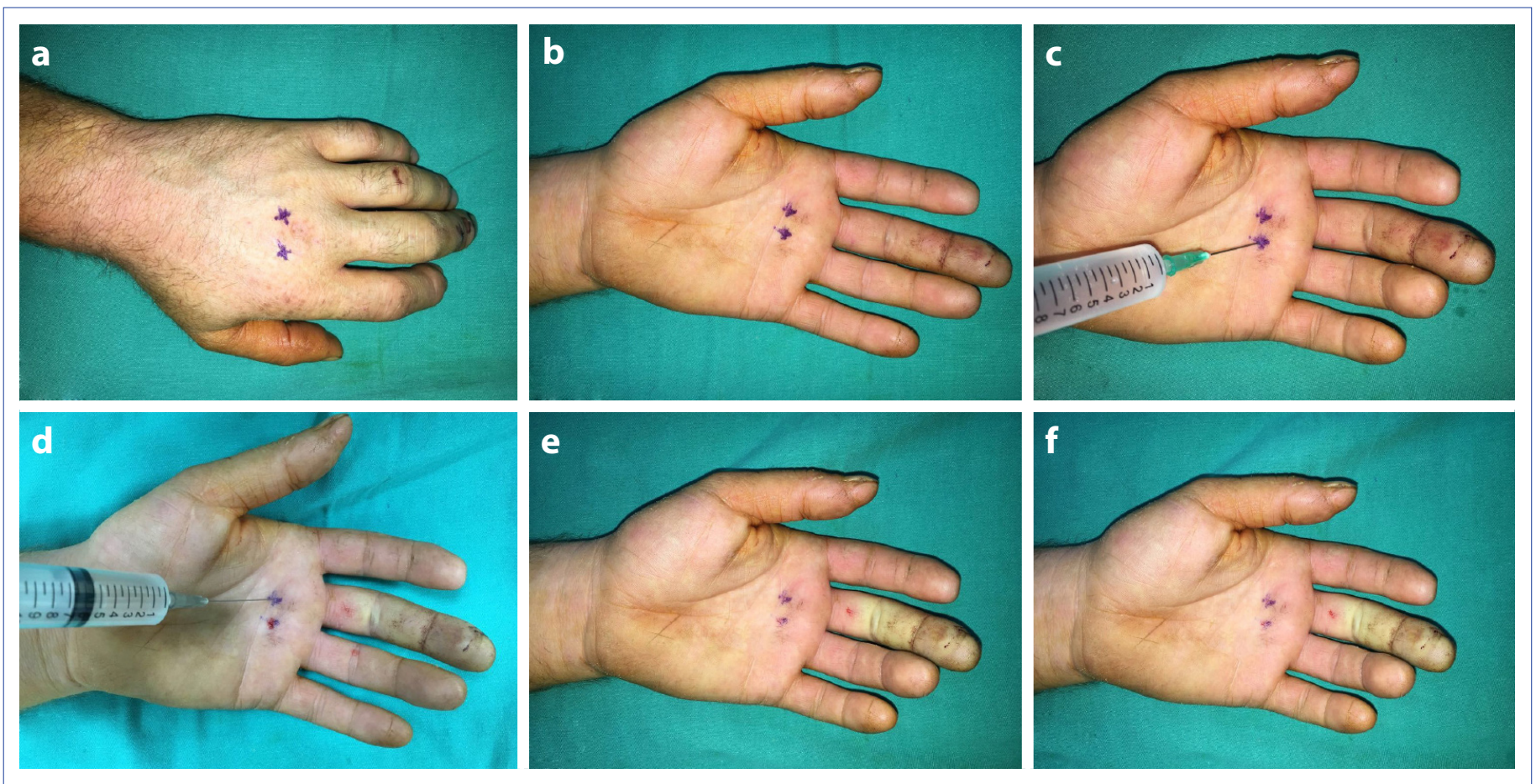

Şekil 1 (a-f). Üçüncü parmağın fleksör pollicis longus tendon rüptüründen muzdarip bir hastanın dorsal ve volar görüntüleri (sol el) (a, b); enjeksiyon prosedürü (c, d); ve mikrovasküler dolaşımın vazokonstriksiyonuna bağlı solukluk (e, f). 
saat (7-38), ameliyata başlama süresi ortalama 5.1 dakika (4-7) olarak değerlendirildi. Aksiller anestezi ile yumuşak doku girişimsel işlem uygulanan hastaların yaş ortalaması 40.6 (19-67), 11'i kadın, 15'i erkekti. Anestezi maliyeti ortalaması 322.7 TL (280-343), ortalama hastanede yatış süresi 31.2 saat (18-46), ameliyata başlama süresi ortalama 38.8 dakika (20-45) olarak değerlendirildi. Aksiller anestezi ile kemik doku girişimsel işlem uygulanan hastaların yaş ortalaması 37.5 (18-76), 10'u kadın, 16'sı erkekti. Anestezi maliyeti ortalaması 309.4 TL (239-343), ortalama hastanede yatış süresi 34.5 saat (24-46), ameliyata başlama süresi ortalama 33.2 dakika (20-45) olarak değerlendirildi.

Hastaların hastanede kalış süreleri saat olarak ameliyat için hastaneye girdikleri süreden çıktıkları süreye kadar hesaplanarak toplandı. Ameliyat maliyetleri cerrahi kararı verildikten sonra hazırlık, kullanılan sarf malzemeleri ve yatış ücretleri çıkarılarak kayıt edildi. Aksiller anestezi turnike uygulamasına olanak sağlarken, uyanık hasta anestezi uygulaması turnike ağrısına sebep olabileceği için turnike uygulaması ağrılı olabilmektedir. Bu nedenle kanama miktarı ölçümleri ameliyat sonrası kanama kontrolü yapıldıktan sonra tespit edilen kanama miktarları olarak belirlendi. Operasyon sonrası kanama miktarları " hiç kanamama, minimal kanama ve turnike gerektirecek miktarda kanama" olarak üçe ayrılarak kayıt edildi. Postoperatif kanama miktarı spancın tutmuş olduğu kanama miktarı (spancın tutmuş olduğu kanama miktarı) baz alınarak yapıldı. Elde edilen veriler iki grup arasında karşılaştıııldı. Operasyon sonrası hastalara "Bu yaşadığın tecrübeyi tekrar yaşaman gerekse aynı anestezi yöntemini kabul eder miydin?" sorusu yöneltildi ve cevapları toplandı.

\section{Bulgular}

Aksiller anestezi grubunda cerrahi girişim ücreti, analjezik ve antibiyotik tedavileri hariç tutularak Sosyal Güvenlik Kurumuna ortalama 316.1 TL maliyet çıkarmasına rağmen uyanık hasta anestezisi grubunda bu miktar 25.3 TL olduğu görüldü. Aksiller anestezi grubunda hastaların ortalama 32.9 saatlerinin hastanede geçtiği görülürken bu rakam uyanık hasta anestezi grubunda 13.6 saat olarak belirlendi. Anestezi sonrası cerrahiye başlama süresi aksiller anestezi grubunda 35 dakika, uyanık hasta anestezisi grubunda 5.3 dakika olduğu ölçüldü. Aksiller anestezi grubu hastalara rutin turnike uygulandığı için kanama sorunu yaşanmadı. Uyanık hasta anestezi grubunun 10 hastasında minimal kanama gözlendi ve basit koagülasyonla cerrahiye devam edildi; 2 hastada ise kanamanın koagülasyonla azalmaması nedeniyle dijital turnike uygulanarak ameliyat tamamlandı (Tablo 1). Uyanık hasta anestezisi grubunda 33 hasta yapılan işlemi aynı anestezi ile tekrar geçirebileceğini belirtirken aksiller
Tablo 1. Uyanık Hasta Anestezisi ve Aksiller anestezinin maliyet, yatış süresi, ameliyata başlama sürelerinin karşılaştırılması (Ortalama, Minimum ve maksimum değerler)

\begin{tabular}{lcc}
\hline & $\begin{array}{c}\text { Uyanık hasta } \\
\text { anestezisi }\end{array}$ & $\begin{array}{c}\text { Aksiller } \\
\text { anestezi }\end{array}$ \\
\hline Anestezi maliyeti (TL) & $25.3(18.5-48.5)$ & $316.1(239-343)$ \\
Yatış süresi (Saat) & $13.6(6-38)$ & $32.9(16-46)$ \\
Ameliyata başlama & $5.3(3-8)$ & $35(20-45)$ \\
Süresi (Dakika) & & \\
Kanama miktarı & 10 Hasta & Tüm Hastalarda \\
& Minimum kanama & Kanama Yok \\
& 2 hasta turnike & \\
& uygulaması & \\
& 40 hasta & \\
& kanama yok & \\
\hline
\end{tabular}

anestezi grubunda bu rakamın 26 olduğu görüldü; bu soruya olumsuz cevap verenlerin sayısı sırasıyla 7 ve 16; kararsızların sayısı ise sırasıyla 12 ve 10 olarak saptandı. Ameliyat sonrası 6. saat değerlendirilen görsel analog skor değerleri ortalaması 0.5 (0-2), uyanık hasta anestezisi uygulanan grupta 3.1 (0-6) olarak değerlendirildi. Uyanık hasta grubunda anlamlı olarak düşük bulunmuştur.

\section{Tartışma}

Üst ekstremite cerrahisi ve özellikle el cerrahisi son yıllarda giderek popülerleşen ve hastane ortamına maruziyeti kısıtlamak ve maddi giderleri azaltmak amacıyla artık gereklilik haline gelen ayaktan hasta tedavisi için uygun bir alandır. ${ }^{[12]}$ Amerika Birleşik Devletleri (ABD) ve çoğu Avrupa ülkesinde ortopedi ve el cerrahisi prosedürlerinin yaklaşık \%70'i hastaneye günübirlik yatış ile yapılmaktadır. ${ }^{[12]}$ El cerrahisi ameliyatlarında; genel anestezi, periferal bölgesel blok, bölgesel intravenöz anestezi, lokal anestezi ile birlikte sedasyon gibi yöntemleri kullanılagelmektedir; son yıllarda bu yöntemlere uyanık hasta anestezisi eklenmiştir. Uyanık hasta anestezisi ile sağlanan ayaktan hasta tedavisi ile operasyon öncesi hazırlık amacıyla yapılan kan tetkikleri, görüntüleme yöntemleri ve konsültasyonları ücretleri ortadan kalkmaktadır. Günübirlik yatış masrafları ve yatak doluluk oranı azalmaktadır. Biz de yapmış olduğumuz çalışmada hastanede kalış saatinde yaklaşık \% 59 azalma elde ettik. Ayrıca hastane masraflarında ortalama \% 93 düşüş meydana geldi.

Uyanık hasta anestezisini mümkün kılan, parmağa yapılan epinefrinin güvenliğinin artık kanıtlanmış olmasıdır. Son yıllarda yapılan çalışmalar epinefrinin parmak dolaşımını bozarak doku ölümü ile sonuçlanan yaygın bilgiyi geçersiz kılmıştır. ${ }^{[13]}$ Epinefrin kullanımı turnike kullanımını gereksiz hale getirir. Böylelikle turnike ağrısının ortadan kalkması sedasyon ve anestezi ihtiyacının da ortadan kalkması an- 
lamına gelmektedir. Turnike kullanımı komplikasyonları olarak görülen kas, sinir, cilt yaralanmaları; kompartman sendromu ve diğer sistemik yan etkiler ile turnike sonrası sendrom olarak adlandırılan ilgili bölgede zayıflık, katılık, ödem, dizestezi ve ağrıyla karekterize durum uyanık hasta anestezisinde gelişsmez. ${ }^{[14]}$ Bunlara ek olarak turnikenin ameliyat zamanını kısıtlayıcı etkisinden de kurtulmuş olur. Çalışmamızda gruplar arasında ameliyat sonrası 6 . saatte ağrı skoru uyanık hasta anestezisi ile yapılan hastalarda anlamlı olarak düşük çıkmıştır. Buna rağmen iki grup arasında ameliyat sırasındaki kanama miktarlarında anlamlı fark çıkmamıştır, sadece 2 hastada turnike gerektirecek kanama gelişmiştir.

Uyanık hasta anestezisinin bir diğer birleşeni olan bikarbonat ise asidik olan lidokainin yakıcı ağrısını azaltmakta ve böylelikle hastayı rahatsız etmeden yüksek miktarda ve çoklu bölgeye yapılmasını mümkün kılmaktadır. ${ }^{[13]}$ Aksiller anestezi sırasında ve uyanık hasta anestezisi sonrasında yapılan anket cevaplarında uyanık hasta anestezisi yapılan hastaların 7'si olumsuz görüş bildirirken bu aksiller anestezi grubunda 16 olarak kaydedilmiştir.

Uyanık hasta anestezisinin en önemli üstünlüğü hastanın operasyon sırasında verdiğimiz komutları yerine getirebiliyor olmasıdır. Lalonde ${ }^{[9]}$ yazısında tendon tamiri sırasında pulleyler altında kaymayı önleyen sıkışıklıkların belirlenmesinde ve giderilmesinde, her dikiş sonrasında tamir hattının aktif hareket ile test edilmesinde üstün olduğunu belirtmektedir. Buna ek olarak tamir sonrasında elde edilen aktif fleksiyonun derecesi görülerek tendon rehabilitasyonunda da yol gösterici olabilmektedir. Bu üstünlükleri sayesinde tendon yapışıklıkları ve tekrar kopma ihtimali azalmaktadır. ${ }^{[9]}$ Bezuhy ${ }^{[10]}$ ise çalışmasında uyanık hasta anestezi ise ekstensör pollicis longusun ekstensör indicis brevis ile rekonstriksiyonu sırasında tendon geriliminin ayarlanması sırasında hastanın uyanık olmasının avantajlarından bahsetmektedir. Hastanın komutları yerine getirebiliyor olmasının tendon tamirleri, rekonstrüksiyon ve transferleri sırasında sağladığı üstünlükleri vakalarımızda biz de gözlemledik. Bunun yanı sıra kırık tespiti sonrası hastada malrotasyon olup olmadığı tespit edilebildiğini de saptadık.

Çalışmamız her ne kadar aksiller anestezi ile uyanık hasta anestezisini karşılaştırıyor olsa da dijital sinir bloğuna göre de üstün yanlarından bahsetmek gerekir. Dijital sinir bloğu parmak dijital sinirleri üstünden yapılan, parmak cerrahisinde yaygın olarak kullanılan blok türüdür. ${ }^{[14-16]}$ Direkt sinir üzerine uygulandığı için epinefrin içermeyen lokal anestezikler kullanılmakta ve kanama kontrolü için sıklıkla parmak turnikeleri kullanılmaktadır. Ayrıca yapılan dijital anesteziğinde mekanik olarak yaptığı arter basısını da unutmamak gerekir. Uyanık hasta anestezisi yönteminde kullanılan epi- nefrin kanama kontrolü sağlayarak turnike ihtiyacını azaltmaktadır. Digital bloğa göre; uygulama kolaylığı, epinefrin içeren ajanlar uygulanabilmesi, turnike gereksinimini ve buna bağlı komplikasyonları olmaması üstün yanları olarak düşünülebilir. Çalışmamızda uyanık hasta anestezisi uyguladığımız 50 hastadaki kanama miktarlarını gözlemlediğimizde 40 hastada hiç kanamasız, 10 hastada bipolar koter ile yapılan basit bir kanama kontrolü gereken cerrahi ortam sağlanmış; 2 hastada ise turnike ihtiyacı gelişmiştir.

\section{Sonuç}

El cerrahisinde ve özellikle parmak operasyonlarında daha kısıtlı bölgelere anestezi uygulanan uyanık hasta anestezisi gibi yöntemlerle maliyet azalmakta, hastanede kalış süresi kısalmakta; hasta memnuniyeti artmaktadır. Ameliyat esnasında hastaların komutları yerine getirebiliyor olması yapılan girişimsel işlemlerin, özellikle tendon onarımlarının doğrulanmasına olanak sağlamaktadır. Kliniğimizde daha önce aksiller anestezi kullanılan olgular bu çalışma sonrasında uyanık hasta anestezisi ile yapılır hale gelmiştir.

\section{Açıklamalar}

Etik Komite Onayı: Çalışma Yerel Etik Kurul tarafından onaylandı. Çıkar Çatışması: Bildirilmemiş̧tir.

Yazarlık Katkıları: Konsept - I.A.Ö., A.K.; Tasarım - I.A.Ö., A.K., M.B.; Kontrol - I.A.Ö., S.A., O.O.; Materyal - I.A.Ö., K.Ö.; Veri toplama ve/veya işleme - I.A.Ö., K.Ö., S.A.; Analiz ve/veya yorumlama I.A.Ö., K.Ö., A.K.; Kaynak taraması - I.A.Ö., K.Ö., O.O.; Yazan - I.A.Ö., A.K.; Kritik revizyon - I.A.Ö.

\section{Kaynaklar}

1. Prasetyono TO. Tourniquet-Free Hand Surgery Using the Oneper-Mil Tumescent Technique. Arch Plast Surg 2013;40:129-33.

2. Wilhelmi BJ, Blackwell SJ, Miller JH, Mancoll JS, Dardano T, Tran A, et al. Do not use epinephrine in digital blocks: myth or truth? Plast Reconstr Surg 2001;107:393-7.

3. Sylaidis $\mathrm{P}$, Logan A. Digital blocks with adrenaline. An old dogma refuted. J Hand Surg Br 1998;23:17-9.

4. Denkler K. A comprehensive review of epinephrine in the finger: to do or not to do. Plast Reconstr Surg 2001;108:114-24.

5. Lalonde D, Bell M, Benoit P, Sparkes G, Denkler K, Chang P. A multicenter prospective study of 3,110 consecutive cases of elective epinephrine use in the fingers and hand: the Dalhousie Project clinical phase. J Hand Surg Am 2005;30:1061-7.

6. Fitzcharles-Bowe C, Denkler K, Lalonde D. Finger injection with high-dose $(1: 1,000)$ epinephrine: Does it cause finger necrosis and should it be treated? Hand (N Y) 2007;2:5-11.

7. Lalonde $\mathrm{DH}$. "Hole-in-one" local anesthesia for wide-awake carpal tunnel surgery. Plast Reconstr Surg 2010;126:1642-4.

8. Lalonde $\mathrm{DH}$. Wide-awake flexor tendon repair. Plast Reconstr 
Surg 2009;123:623-5.

9. Lalonde D. Minimally invasive anesthesia in wide awake hand surgery. Hand Clin 2014;30:1-6.

10. Bezuhly M, Sparkes GL, Higgins A, Neumeister MW, Lalonde DH. Immediate thumb extension following extensor indicis proprius-to-extensor pollicis longus tendon transfer using the wide-awake approach. Plast Reconstr Surg 2007;119:1507-12.

11. Higgins A, Lalonde DH, Bell M, McKee D, Lalonde JF. Avoiding flexor tendon repair rupture with intraoperative total active movement examination. Plast Reconstr Surg 2010;126:941-5.

12. Ketonis $C$, llyas $A M$, Liss F. Pain management strategies in hand surgery. Orthop Clin North Am 2015;46:399-408.
13. Lalonde D. How the wide awake approach is changing hand surgery and hand therapy: inaugural AAHS sponsored lecture at the ASHT meeting, San Diego, 2012. J Hand Ther 2013;26:175-8.

14. Prasetyono TO, Biben JA. One-per-mil tumescent technique for upper extremity surgeries: broadening the indication. J Hand Surg Am 2014;39:3-12.e7.

15. Frank SG, Lalonde DH. How acidic is the lidocaine we are injecting, and how much bicarbonate should we add? Can J Plast Surg 2012;20:71-3.

16. Steven D. Waldman MD. Metacarpal and Digital Nerve Block Atlas of Interventional Pain Management. 4thed. Philadelphia: Elsevier Saunders; 2015. p. 275-8. 